1891.

${ }^{23}$ O. de Buen. Bull. Soc. Zool. France 30: 98-106. 1905; O. de Buen. Bol. Soc. Esp. Hist. Nat. 6: 173-180. 1906.

24“"En verdad que está muy abandonada esta especialidad por nuestros naturalistas [...] Contribuyen al abandono, en primer término, las dificultades de la recolección y del estudio; hay que disponer de dragas y embarcaciones a propósito, que motivan gastos de alguna cuantía, dada nuestra pobreza; hay que arrostrar las fatigas de la pesca del bou, o retribuir bien y adiestrar a los pescadores, y hay que contar con microscopio, bastante material y costosa biblioteca" (O. de Buen. Bol. Soc. Esp. Hist. Nat. 6: 173-180. 1906, cf. p. 179).
${ }^{25}$ F.J. Dosil Mancilla. Op. cit. nota 1, p. 4.

${ }^{26} \mathrm{~F}$. Bellón. Boletín de Pescas 56-58: 81-119. 1921.

${ }^{27} \mathrm{O}$. de Buen. Note sur les fonds et sur la pêche dans la côte méditerranéenne du Riff. [Extracto de las Actas del V Congresso Internazionale di Pesca]. Roma, 1913.

${ }^{28}$ Con la nomenclatura actual: Peyssonnelia polymorpha (Zanardini) F. Schmitz, Halopteris filicina (Grateloup) Kützing y Zanardinia collaris (Montagne) P.L.Crouan \& H.M.Crouan.

Dirección del autor. Centro Oceanográfico de Málaga. Instituto Español de Oceanografía. Muelle Pesquero s/n.29.640Fuengirola (Málaga).jprubin@ ma.ieo.es

\title{
48. UNA MUESTRA DEL HERBARIO DE ALGAS DE ODÓN DE BUEN (1863-1945) EN UNA CROMOLITOGRAFÍA DE 1907
}

\author{
Juan PÉREZ-RUBÍN
}

Una cromolitografía sobre macroalgas españolas, publicada en $1907^{1}$, dentro de un trabajo de carácter divulgativo elaborado por Odón de Buen², incluye un total de 26 especies; en esta nota aportamos una revisión taxonómica de todo el lote, valoramos la presencia/ausencia de especies concretas y discurrimos sobre el origen bibliográfico de las imágenes que pudieron inspirar al dibujante (R. Costa) como complemento imprescindible a su examen de los ejemplares de herbario.

La cromolitografía con la selección de ejemplares del herbario personal de O. de Buen se publicó en la Enciclopedia Ilustrada Seguí, la cual fue viendo la luz por entregas mensuales; los cuadernos que contenían el texto e ilustraciones sobre 'Algas' se pusieron a la venta a partir de agosto de $1907^{3}$.

No está claro que fuera Odón de Buen el encargado de seleccionar los 26 taxones concretos y aportar al dibujante, Ramón Costa Nolla (Reus, n. 1877), las fuentes impresas con las imágenes más realistas de las algas elegidas para facilitar la difícil tarea de dar un aspecto vivo a los resecos y descoloridos ejemplares de herbario. Únicamente tres de los diez géneros representados en la estampa en color del primer tomo del manual de Botánica... publicado por Odón de Buen en $1891^{4}$ aparecen en la cromolitografía analizada: Callithamnium, Plocamium y Polysiphonia, y sus representaciones son totalmente distintas. 


\begin{tabular}{|c|c|c|}
\hline Taxón citado & Nomenclatura actual & Autores anteriores \\
\hline \multicolumn{3}{|c|}{ Taxones de la fitoteca de Odón de Buen } \\
\hline Bryopsis plumosa & Bryopsis plumosa (Hudson) C.Agardh & Rodríguez; Lázaro \\
\hline Caulerpa prolifera & Caulerpa prolifera (Forsskål) J.V.Lamouroux & Rodríguez \\
\hline Ceramium diaphanum & Ceramium diaphanum (Lightfoot) Roth & Rodríguez \\
\hline Ceramium echionotum & Ceramium echionotum J.Agardh & Rodríguez \\
\hline Halymen patens & $\begin{array}{l}\text { Kallymenia patens (J. Agardh) Codomier ex } \\
\text { P.G.Parkinson }\end{array}$ & Rodríguez \\
\hline Halyseris polypodioides & Haliseris polypodioides (DC) C.Agardh & Rodríguez \\
\hline Laurencia pinnatífida & Osmundea pinnatifida (Hudson) Stackhouse & Rodríguez \\
\hline Liebmannia leveillei & Liebmannia leveillei J.Agardh & Rodríguez \\
\hline Lomentaria phalligera & Lomentaria articulata var. linearis Zanardini & Rodríguez \\
\hline Nemastoma cervicornis & Platoma cyclocolpum (Montagne) F.Schmitz & Rodríguez \\
\hline $\begin{array}{l}\text { Nitophyllum punctatum var. } \\
\text { ocellatum }\end{array}$ & Nitophyllum punctatum (Stackhouse) Greville & Rodríguez; Lázaro \\
\hline Nitophyllum uncinatum & Cryptopleura ramosa (Hudson) L.Newton & Rodríguez \\
\hline Plocamium coccineum & Plocamium cartilagineum (L.) P.S.Dixon & Rodríguez; Lázaro \\
\hline Polysiphonia brodiaei & Polysiphonia brodiei (Dillwyn) Sprengel & \\
\hline Porphyra leucosticta & Pyropia leucosticta (Thuret) Neefus \& J.Brodie & Rodríguez; Lázaro \\
\hline Udotea desfontainii & Flabellia petiolata (Turra) Nizamuddin & Rodríguez \\
\hline Ulva lactuca & Ulva lactuca $\mathrm{L}$. & Rodríguez; Lázaro \\
\hline Zonaria flava & Zonaria tournefortii (J.V.Lamouroux) Montagne & Rodríguez \\
\hline \multicolumn{3}{|c|}{ Taxones no incluidos en la fitoteca de Odón de Buen } \\
\hline Callithamnion borreri & Pleonosporium borreri (Smith) Nägeli & Rodríguez \\
\hline Fucus vesiculosus & Fucus vesiculosus L. & Lázaro \\
\hline Lithothamnion fasciculatum & Lithophyllum fasciculatum (Lam.) Foslie & Lázaro \\
\hline Valonia utricularis & Valonia utricularis (Roth) C.Agardh & Rodríguez \\
\hline Agarum gmelini & Agarum clathratum Dumort. & \\
\hline Caulerpa scalpelliformis & $\begin{array}{l}\text { Caulerpa scalpelliformis (R.Brown ex Turner) } \\
\text { C.Agardh }\end{array}$ & \\
\hline Chaetomorpha darwinii & Chaetomorpha coliformis (Montagne) Kützing & \\
\hline Stypocaulon scoparium & Halopteris scoparia (L.) Sauvageau & \\
\hline
\end{tabular}

Tabla 1. Actualización taxonómica de las especies de algas incluidas en la estampa, reagrupadas en dos subconjuntos por orden alfabético, con indicación de las citadas anteriormente por J.J. Rodríguez Femenías [Rodríguez] y por B. Lázaro Ibiza [Lázaro]. 
Con respecto al segundo tomo ${ }^{5}$, solamente está representada una de las treinta especies españolas citadas, Ulva lactuca, y uno de los ocho géneros considerados en el mismo: Chaetomorpha.

Tampoco en el texto del artículo 'Algas' de la enciclopedia Seguí [tomo I: 429-431] hay certeza sobre los criterios seguidos para la selección de las especies concretas de la estampa ni bibliografía, aunque se incluye una interesante figura esquemática sobre la "Reproducción de las algas", firmada por el mismo dibujante: R. Costa. Se mencionan en el referido artículo unos treinta taxones de macroalgas: solo media docena "propios de nuestros mares" y los restantes en función de sus características morfológicas distintivas o variados aprovechamientos. Están presentes cuatro de esos taxones referenciados en la cromolitografía analizada aquí: Ulva lactuca, Lithothamnion, Lithophyllum y 'las caulerpas', así como otros nueve taxones en una estampa complementaria del mismo dibujante, más artística $^{6}$, y que no vamos a analizar aquí.

Podemos concluir que la estampa con los ejemplares de Odón de Buen muestra, mayoritariamente, especies presentes en las aguas españolas, la mayor parte de ellas, 21 de los taxones ilustrados $(81 \%)$, referenciadas en los amplios catálogos de de Juan Joaquín Rodríguez Femenías (1839-1905) y Blas Lázaro Ibiza (1858-1921), fechados en 18897. Dominan las especies mediterráneas pues, desglosando esas citas por su origen geográfico, resulta que, en ese lote, según la información de la época, ya podía distinguirse entre especies probablemente más frecuentes en el Mediterráneo (14 citadas exclusivamente por Rodríguez Femenías) y en el Atlántico (dos mencionadas por Lázaro Ibiza), así como las presentes en ambas áreas (cinco referencias conjuntas).

Un examen de las ilustraciones que se incluyen en la iconografía referida muestra que hay taxones que no presentan dudas, pero otros son de imposible identificación atendiendo a un icono e, incluso en algún caso, aunque tuviéramos el ejemplar de herbario en las manos (como ocurre con las dos especies de Ceramium sólo diferenciables al microscopio y cuyos dibujos parecen casi iguales). Particularmente dudosos son la Coralinácea que aparece como Lithothamnion fasciculatum y el ejemplar de Nemastoma cervicornis (que muy bien podría ser una especie de Predaea). Otra dificultad añadida se presenta en algunos géneros taxonómicamente complejos a los que se les aplica el específico 'habitual', como los casos de Ulva 'lactuca' o Plocamium 'coccineum', por lo que también es difícil deducir su identidad real ${ }^{8}$ (véase tabla 1 ).

Para el subconjunto mayoritario de dieciocho especies correspondientes a la ficoteca de $\mathrm{O}$. de Buen se concretaba al pie de la estampa que "corresponden a especies de algas del Mediterráneo", reflejando el interés editorial y/o de Odón de Buen por dar preferencia a especies nacionales mediterráneas. La mayoría estudiadas en las islas Baleares por Rodríguez Femenías (1889) y, en cinco casos, también halladas por Lázaro Ibiza en el Atlántico (1889). Además se incluyen taxones, como los géneros Platoma, Osmundea y Zonaria, que hoy sabemos que son realmente más característicos de aguas con mayor influencia atlántica, como las del estrecho de Gibraltar y mar de Alborán. Incluso en cinco especies se trata de taxones que ya se sabía entonces que eran igualmente representativos del Atlántico peninsular, al estar incluidas en el coetáneo catálogo de Lázaro e Ibiza (1889) sobre ejemplares de las costas gallegas y del Cantábrico.

Por otro lado, las restantes ocho especies ajenas a la colección de $\mathrm{O}$. de Buen, incluyen una mitad de taxones españoles citados en 1889 y los restantes exóticos. Estos pueden subdividirse, con la bibliografía actual, según su distribución geográfica mundial sea amplia: Caulerpa scalpelliformis y Stypocaulon scoparium) o 
muy reducida: Agarum gmelini (Alaska) y Chaetomorpha darwinii (Sudamérica).

Con respecto a la treintena de taxones enumerados por Odón de Buen en 1905 y 1906 únicamente aparecen en la estampa cinco de ellos, ya citados por Rodríguez Femenías: Caulerpa prolifera, Halyseris polipodioides, Lomentaria phaligera y los géneros Udotea y Valonia.

Sorprende, particularmente, la ausencia en la estampa de la imagen de una bella especie mediterránea, endémica y muy representativa, dedicada al más destacado algólogo español de la época, y que el propio O. de Buen definió como "la más hermosa de las algas de la región: la Laminaria Rodriguezii""; le fue dedicada, en 1888, por el especialista francés E. Bornet $(1818-1911)^{10}$, quien orientó sus primeros pasos en la materia y redactó su necrológica ${ }^{11}$.

Aunque tampoco se han incluido la media docena de especies que el propio autor menorquín dibujó y fue publicando, al menos aparecen representados en la estampa varios de sus géneros predilectos: Nitophyllum y Halymenia/Kallymenia ${ }^{12}$. El actual reconocimiento internacional a este especialista balear, dedicado a la algología desde los años 1870 y que mantuvo correspondencia científica con, al menos, 34 eminentes algólos extranjeros identificados ${ }^{13}$, se materializa en una veintena de taxones algológicos con referencia a su persona ${ }^{14}$. El género Rodriguezella le fue dedicado en 1870 por F. Schmitz (in litt), aunque no sería válidamente publicado hasta 1895, por el propio J. J. Rodríguez Femenías ${ }^{15}$.

Para finalizar, repasando fuentes extranjeras, encontramos una coincidencia en la selección de un total de quince especies ( 58 $\%$ que, en su mayoría, aparecen representadas gráficamente, aunque con claras diferencias morfológicas, en la obra de Harriot $(1892)^{16}$ con láminas fotográficas y en la estampa que ilustra la edición de la enciclopedia Larousse del año 1906.

Podemos concluir que, en la selección de taxones presentados en la estampa ficológica publicada por la Enciclopedia Segui, primaron los criterios estéticos y la idea de mostrar la gran diversidad morfológica y cromática de las algas.

AGRADECIMIENTOS. Al Dr. Javier Cremades Ugarte (Universidad de A Coruña) por su valiosa ayuda prestada con la revisión de las actualizaciones taxonómicas y sus comentarios enriquecedores; $\mathrm{a} \mathrm{D}^{\mathrm{a}}$ María José Martínez de la Rosa y a la Dra. Paloma Blanco Fernández de Caleya (Real Jardín Botánico de Madrid. CSIC ) por facilitarme una copia completa del artículo 'Algas' de la Enciclopedia

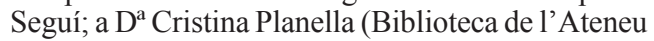
de Maó) por la ayuda para completar nuestra bibliografía sobre Rodríguez Femenías; y a $\mathrm{D}^{\mathrm{a}}$ Roser Pintó Fàbregas (Unitat Gràfica, Biblioteca de Catalunya) por la identificación del artista R. Costa.

\section{Notas}

${ }^{1}$ La cromolitografía ha sido reproducida recientemente por J. Pérez-Rubín. Bol. R. Soc. Esp. Hist. Nat. Secc. Aula, Museos y Colecciones 1: 57-72. Madrid, 2014.

${ }^{2}$ O. de Buen. 'Algas'. En: Diccionario Universal con todas las Voces y Locuciones Usadas en España y en América Latina, 1(1): lám. 2. Barcelona: Ed. Segui, 1910.

3La Vanguardia (Barcelona), 21/8/1907: 9; el periódico anuncia la puesta en el mercado de los cuadernos 36, 37 y 38 donde tienen cabida las palabras comprendidas entre 'Alfonso' y 'Almacén'.

${ }^{4}$ O. de Buen. Botánica con inclusión de la Geografia Botánica. Tomo I. Barcelona: Montaner y Simón, 1891.

${ }^{5} \mathrm{O}$. de Buen. Botánica con inclusión de la Geografia Botánica. Tomo II. Barcelona: Montaner y Simón, 1892.

${ }^{6}$ Reproducida por J. Pérez-Rubín en J.M. Losada (ed.) Abordajes, mitos y reflexiones sobre el mar: 81-102. Madrid: Instituto Español de Oceanografía, 2014.

${ }^{7}$ J.J. Rodríguez Femenías. Anales Soc. Esp. Hist. Nat. 18: 199-274. 1889; B. Lázaro Ibiza. Anales Soc. Esp. Hist. Nat. 18: 276-294. 1889.

${ }^{8}$ Todas las apreciaciones técnicas de este párrafo son del especialista J. Cremades (Universidad A Coruña), al que estamos muy agradecidos por su colaboración.

${ }^{9}$ O. de Buen. Bol. Soc. Esp. Hist. Nat. 6: 173-180. 
1906.

${ }^{10} \mathrm{El}$ ejemplar estudiado, habitante de fondos de 125-150 m, fue descubierto en 1885 a $12 \mathrm{Km}$ de la costa (E. Bornet. Bull. Soc. Bot. France 35: 361-366. 1888).

${ }^{11}$ E. Bornet. Bull. Soc. Bot. France 52: 490. 1905.

12"'Por el estudio del herbario [de Rodríguez Femenías] se comprueba que se ocupó especialmente de los géneros Nitophylum, Halymenia, Kallymenia, Neurocaulon, Cryptonemia y Delesseria" (J. Seoane-Camba. Revista de Menorca, 71: 7-23. 1980, cf. p. 11).

${ }^{13} \mathrm{~J}$. Seoane-Camba. Op. cit. nota 12.

${ }^{14}$ En AlgaeBase encontramos veintidós taxones en relación directa con J.J. Rodríguez Femenías: Cladophora falcata var. hamifera, Constantinea grandifolia, Cystoseira abrotanifolia var. leptocarpa Cystoseira abrotanifolia var. squarrosa, Delesseria balearica, Fauchea microspora, Gloiocladia microspora, Myriogramme carnea, $M$. tristromatica, Neurocaulon grandifolium, seis especies de Nitophyllum (N. carneum, $N$. distromaticum, N. magontanum, N. marmoratum, $N$. nitidum y $N$. tristromaticum), Polysiphonia subulata f. vestita, Sphaerococcus rhizophylloides, Ulva lactuca var. perforata, Rodriguezella strafforelloi y $R$. bornetii. Aparte, este género cuenta con otras seis especies de diferentes autores: Rodriguezella hongngai, $R$. ligulata, $R$. pelagosae [Osmundea pelagosae], $R$. pennata, $R$. pinnata y $R$. rhizophylla. (W. Guiry in M.D. Guiry, G.M. Guiry. AlgaeBase. World-wide electronic publication. Galway: National University of Ireland, 2015 [http://www.algaebase.org; searched on 18 March 2015].

${ }^{15}$ Fue el propio Rodríguez Femenías quien, cuando publicó en aquel año (1890) la descripción de la nueva especie Cladhymenia Bornetii, indicaba "ya entonces que quizá sería necesario establecer un nuevo género, si el estudio detenido de la planta venía á demostrar que su tipo de crecimiento difería de las demás especies de Cladhymenia. Y en efecto, sometida al examen del Sr. Schmitz, se cercioró de que mi planta carecía de eje central y debía, por tanto, separarse de los Cladhymenia [...]. En una carta que me dirigió en Junio de 1870 estableció este nuevo género, y tuvo la galantería de dedicármelo [...]. Bajo la denominación de $C l$. Bornetii yo había comprendido dos especies diferentes, y ambas entran en el nuevo género Rodriguezella. Una de ellas dedicóla el Sr. Schmitz al Sr. Strafforello, que la había recogido años hace en estado estéril en las costas de Liguria. Es posible que el Sphaerococcus Palmetta, var. pinnata Kg., sea una tercera especie de este género" (J.J. Rodríguez Femenías. Anales Soc. Esp. Hist. Nat. 24: 155-162.1895, la cita en p. 157-158).

${ }^{16} \mathrm{P}$. Harriot. Atlas des algues marines les plus répandues des côtes de France. Paris, 1892.
Dirección del autor: Centro Oceanográfico de Málaga. Instituto Español de Oceanografía. Muelle Pesquero s/n. 29.640 Fuengirola (Málaga). Dirección de contacto: jprubin@ma.ieo.es 